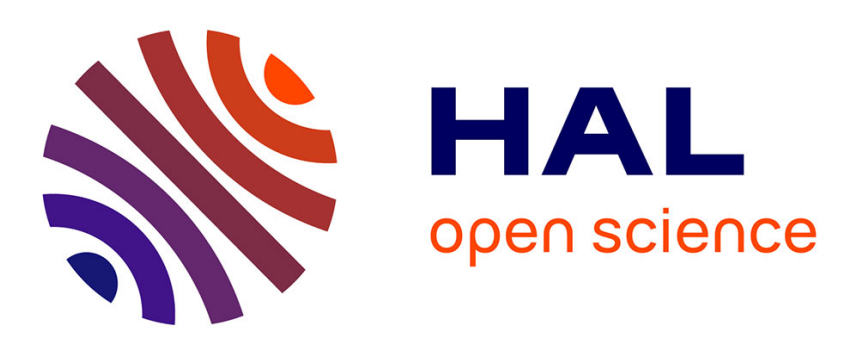

\title{
Small end-fire superdirective folded meandered monopole antenna array
}

Mohamad Hammoud, Abdullah Haskou, Ala Sharaiha, Sylvain Collardey

\section{To cite this version:}

Mohamad Hammoud, Abdullah Haskou, Ala Sharaiha, Sylvain Collardey. Small end-fire superdirective folded meandered monopole antenna array. Microwave and Optical Technology Letters, 2016, 58 (9), pp.2122-2124. 10.1002/mop.29995 . hal-01338399

\section{HAL Id: hal-01338399 https://hal-univ-rennes1.archives-ouvertes.fr/hal-01338399}

Submitted on 28 Jun 2016

HAL is a multi-disciplinary open access archive for the deposit and dissemination of scientific research documents, whether they are published or not. The documents may come from teaching and research institutions in France or abroad, or from public or private research centers.
L'archive ouverte pluridisciplinaire HAL, est destinée au dépôt et à la diffusion de documents scientifiques de niveau recherche, publiés ou non, émanant des établissements d'enseignement et de recherche français ou étrangers, des laboratoires publics ou privés. 


\title{
Small End-Fire Superdirective Folded Meandered Monopole Antenna Array
}

\author{
Mohamad Hammoud, Abdullah Haskou, Ala Sharaiha, and Sylvain Collardey \\ IETR UMR CNRS 6164- Université de Rennes 1, Rennes, France; \\ Corresponding author: abdullah.haskou@univ-rennes1.fr
}

\begin{abstract}
In this letter, we present a compact four-element superdirective antenna array operating at $900 \mathrm{MHz}$ frequency band. In this antenna, only one element is excited while the others are parasitic-loaded elements. The antenna total dimensions are $231 \times 122 \mathrm{~mm}^{2}$ and it has a total directivity of $11.6 \mathrm{dBi}$ and radiation efficiency of $46 \%$. This antenna is significantly compact compared with others presenting the same directivity.
\end{abstract}

Keywords-Antenna array, superdirectivity, directivity, efficiency

\section{INTRODUCTION}

Some emerging wireless technologies require precise beam pointing in useful directions. Directional small-size antennas allow the development of new opportunities for their applications in terms of spectral efficiency, radio interferencefree deployment, reduced environmental impact, and reducing exposure to electromagnetic fields. Since the pioneering works of I. Uzkov [1] and E.N. Gilbert and S.P. Morgan [2], significant research has been done on superdirective arrays [38]. Early works were conducted primarily on the design of wire antenna arrays [3-4]. Recently, several miniaturized planar parasitic superdirective antennas were presented [5-7]. One of the main issues of this kind of arrays is the poor radiation efficiency when we increase the number of the elements [8]. In [9] we have shown that as we increase the number of the elements in a superdirective array, we should also increase the inter-element spacing to obtain a good efficiency with a high directivity. In this letter, and based on this idea, we design an efficient and impedance-matched compact four-element parasitic superdirective antenna array. The proposed antenna is significantly smaller than commercial antennas with the same directivity. The rest of the letter is organized as follows: The proposed antenna geometry is described in section II. The simulation and experimental results are presented in section III. Finally, conclusions are drawn in section IV.

\section{ANTENNA GEOMETRY AND EXCITATION COEFFICIENTS}

The unit element used in this array is a folded meandered monopole printed on a Rogers duroid/ RT5880 substrate $\left(\epsilon_{r}=2.2, \tan (\delta)=0.0009\right)$ with a thickness of $0.8 \mathrm{~mm}$ (Fig. 1(a)). Its size is $122 \times 31 \mathrm{~mm}^{2}$. It has a simulated (ANSYS HFSS [10]) resonance frequency around $900 \mathrm{MHz}$ with a quasi-omnidirectional radiation pattern (a total directivity of $2.4 d B i$ (Fig. 1(b))) and a radiation efficiency of around $100 \%$.

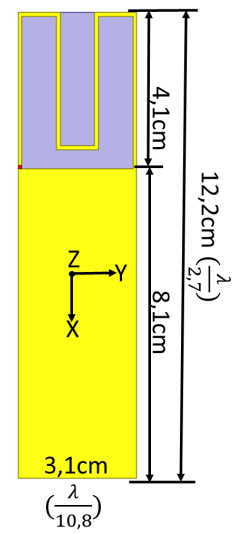

(a)

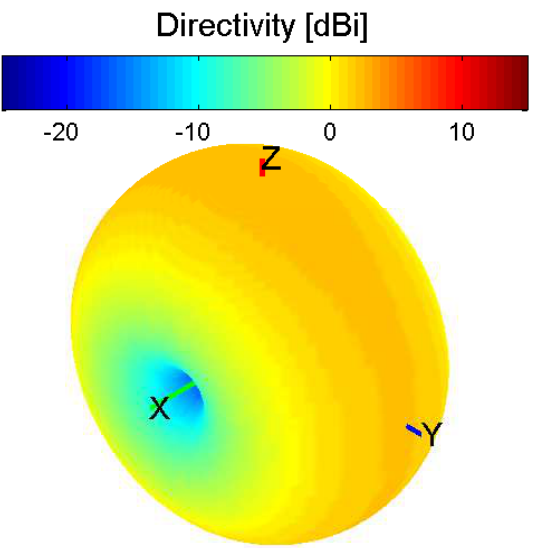

(b)
Fig. 1. The unit-element. (a) Geometry and dimensions and (b) simulated $3 \mathrm{D}$ total directivity radiation pattern.

The method proposed in [9] has been used to design a fourelement array operating at $900 \mathrm{MHz}$ frequency band with an inter-element spacing is $0.2 \lambda$ due to the trade off between the antenna- dimensions, -directivity and -radiation efficiency [9]. The total size of the array is $231 \times 122 \mathrm{~mm}^{2}\left(\frac{\lambda}{1.4} \times \frac{\lambda}{2.7}\right)$. First, the array current excitation coefficients were calculated to maximize the antenna directivity in the end-fire direction $\left(\phi=90^{\circ}, \theta=90^{\circ}\right)$. The obtained excitation coefficients are given in Table 1 (refer to Fig. 2 for elements order). Then, the array is transformed to a parasitic-loaded one where one element is excited while the others are loaded as explained in [9]. The values of the required optimal loads are given in Table 1. As it can be noticed some negative resistances are required, neglecting these resistances and loading the parasitic elements with the lumped elements given in Table 1, total directivities of $8.4,11.6,10.4$ and $8.2 \mathrm{dBi}$ can be achieved in case of exciting the first, second, third or fourth element respectively. For example, when exciting the first element, the second, third and fourth are respectively loaded with $34.74 \mathrm{pF}$, $7.6 p F$ and $61.2 \Omega / / 77.5 n H$. The significant decrement in the parasitic array directivity when exciting the first or fourth element is due to neglecting important negative resistances and the high sensitivity of the antenna directivity to the excitation coefficients as the number of elements increases [9]. In analogy, the achieved directivity when exciting the second element is the highest due to the small values of the neglected 
resistances and since the coupling with the other elements is the highest. Fig. 2 shows that the parasitic (when exciting the second element) array's simulated surface current distribution is in a very good agreement with the fully-driven array's one. In the next section, we shall detail the simulated and measured results for the parasitic array.

TABLE I. THE CALCULATED EXCITATION COEFFICIENTS, THE EQUIVALENT LOADS AND THE APPLIED LOADS.

\begin{tabular}{|l|l|l|l|l|}
\hline Element & 1 & 2 & 3 & 4 \\
\hline Excitation [A] & 1 & $2.26 e^{j-154.8^{\circ}}$ & $2.24 e^{j 45^{\circ}}$ & $1.07 e^{j-114.4^{\circ}}$ \\
\hline Optimal load $[\Omega]$ & $-4.79+j 40.37$ & $-19.02-j 5.09$ & $-j 23.91$ & $39.48+j 0.3$ \\
\hline Applied load & $12 n H$ & $34.74 p F$ & $7.6 p F$ & $61.2 \Omega / / 77.5 n H$ \\
\hline
\end{tabular}

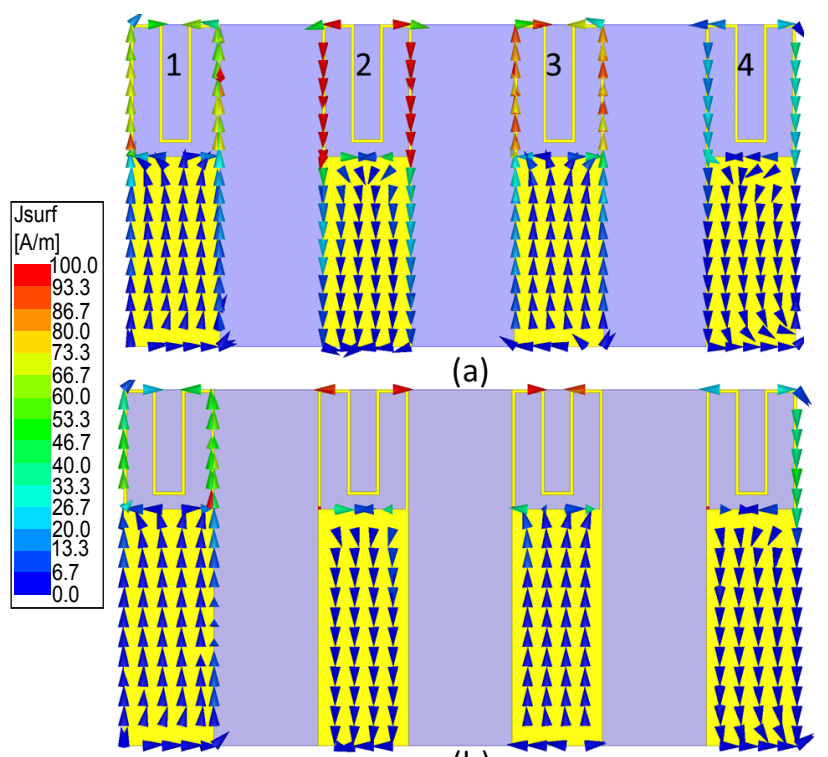

(b)

Fig. 2. The surface current distribution in (a) fully-driven array and (b) parasitic array.

\section{Simulation AND EXPERIMENTAL RESUlTS}

A prototype of this antenna was fabricated and measured to validate the results (Fig. 3(a)). Fig. 3(b) shows that the array measured input reflection coefficient is in a very good agreement with the simulated one. The simulated $\left(S_{11}<-10 d B\right)$ impedance bandwidth is around $7 \mathrm{MHz}$ while the measured one is $6 \mathrm{MHz}$. The antenna far-field radiation pattern was measured using SATIMO Stargate SG 32 measuring system. Fig. 3(c) shows the array maximum total directivity as a function of the frequency. The figure shows that this directivity is highest at the the design frequency with a $\left(D_{\max }-1 d B\right)$ directivity bandwidth of $28.6 \mathrm{M} \mathrm{Hz}$ in simulation and $34 \mathrm{M} \mathrm{Hz}$ in measurement. It can be noted from Fig. 4 that the parasitic array 3D total directivity radiation pattern is in a very good agreement with the fully-driven array's one. Concerning the parasitic array, the figure shows that the antenna is directive with a simulated directivity of $11.6 \mathrm{dBi}$ and a measured one of $11 \mathrm{dBi}$. This directivity is $1.2 \mathrm{dBi}$ higher than Harrington's normal directivity limit for an antenna with the same size factor $(k a=2.46)$ [11]. The Half Power BeamWidth (HPBW) in horizontal (XoY) and vertical (YoZ) planes are respectively $48^{\circ}$ and $58^{\circ}$ in simulation and $45^{\circ}$ and $56^{\circ}$ in measurement. The simulated Front to Back Ratio (FBR) is $18.3 d B$ while the measured one is $13 d B$ (Fig. 5). Fig. 3(d) shows the antenna radiation efficiency. It can be noticed that this efficiency rapidly decreases when approaching the design frequency. This is mainly due to the superdirectivity phenomena; where the current opposition on the different elements cancels the antenna radiation in certain directions, and hence, reduces its radiation efficiency. The antenna has a simulated radiation efficiency of $46 \%$ (a gain of $8.3 \mathrm{dBi}$ ) and an experimental one (measured in a reverberation chamber [12]) of $47.3 \%$ (a gain of $8 d B i$ ). The antenna 3D co-polar directivity radiation pattern given in Fig. 6 shows a very good agreement between the simulated and measured patterns. The maximum co-polar directivity is also in the end-fire (oY) direction with a simulated value of $11.6 \mathrm{dBi}$ and a measured one of $11 \mathrm{dBi}$. The antenna cross-polar 3D directivity radiation pattern is given in Fig. 7. The maximum cross-polar directivity is in the broadside (oZ) direction and it has a simulated value of $-4.7 d B i$ and a measured one of $-1.2 \mathrm{dBi}$. The small difference between simulated and measured results can be attributed to the cable effect, the uncertainties in the SMD components values and measuring system and environment. This antenna is very compact compared to others presenting the same directivity. A Yagi-Uda antenna with the same directivity is around $535 \times 175 \times 40 \mathrm{~mm}^{3}$ [13].

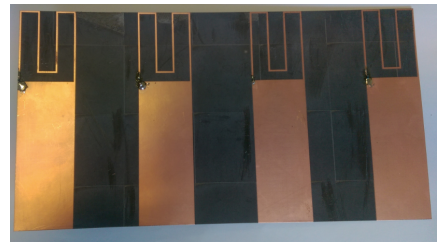

(a)

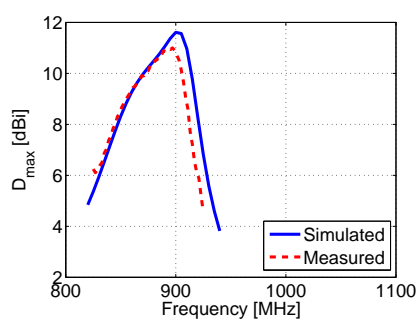

(c)

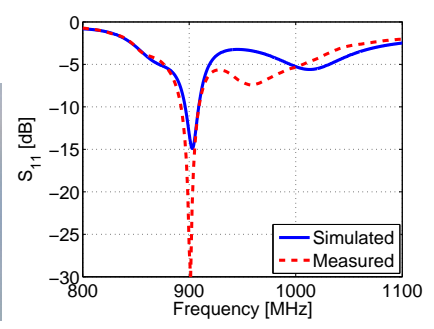

(b)

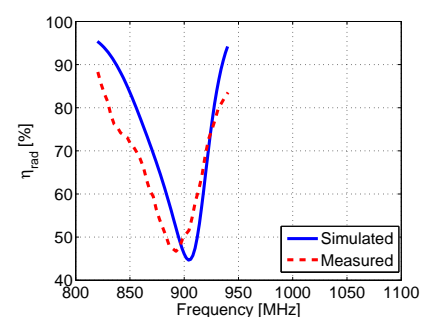

(d)
Fig. 3. Parasitic array simulated and measured parameters. (a) A photograph of the realized prototype, (b) input reflection coefficient magnitude in $\mathrm{dB}$, (c) maximum total directivity and (d) radiation efficiency. 
(a)

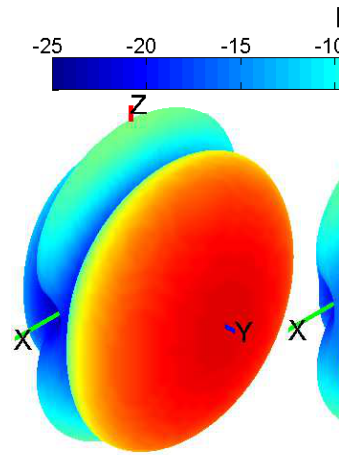

Directivity [dBi]

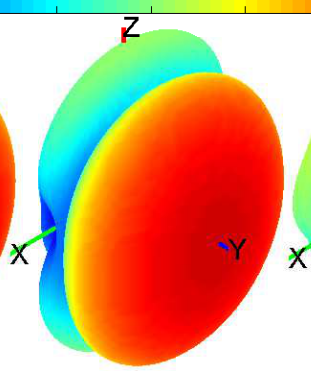

(b)

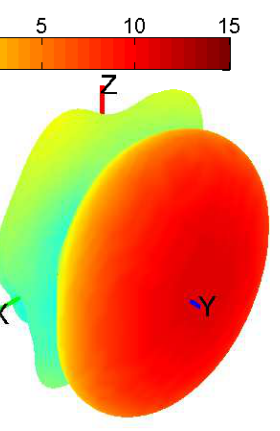

(c)
Fig. 4. Proposed array 3D total directivity radiation pattern. (a) Simulated driven, (b) simulated parasitic and (c) measured parasitic.

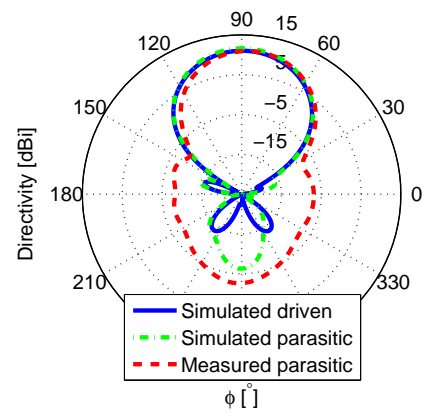

(a)

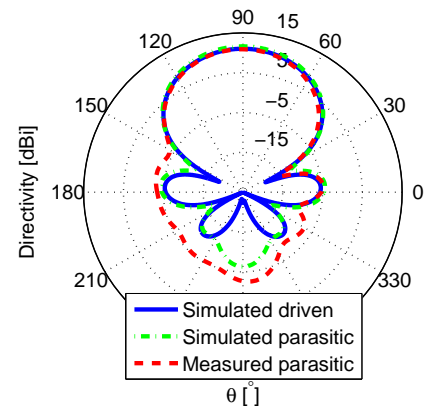

(b)
Fig. 5. Proposed array simulated and measured 2D total directivity radiation pattern. (a) Horizontal plane and (b) vertical plane.

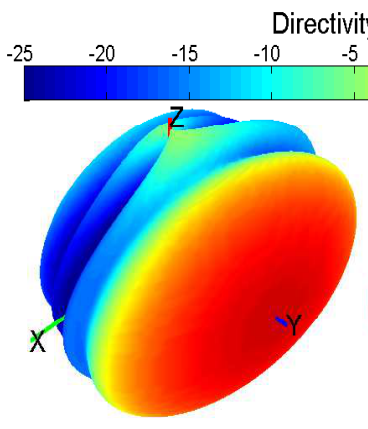

(a)

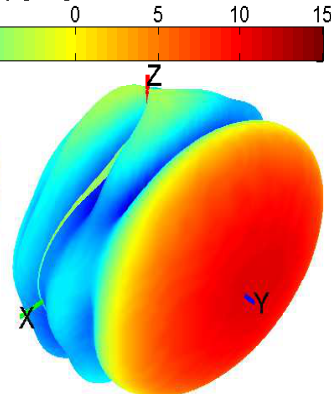

(b)
Fig. 6. Parasitic array 3D co-polar directivity radiation pattern. (a) Simulated and (b) measured.

\section{CONCLUSION}

In this letter, we presented a compact four-element parasiticloaded superdirective array for $900 \mathrm{MHz}$ frequency band for UHF RFID readers. The antenna dimensions were $231 \times$ $122 \mathrm{~mm}^{2}$ and it presented a total directivity of $11.6 \mathrm{dBi}$ and a radiation efficiency of $46 \%$. This array is significantly compact compared with antennas with the same directivity available in the market.

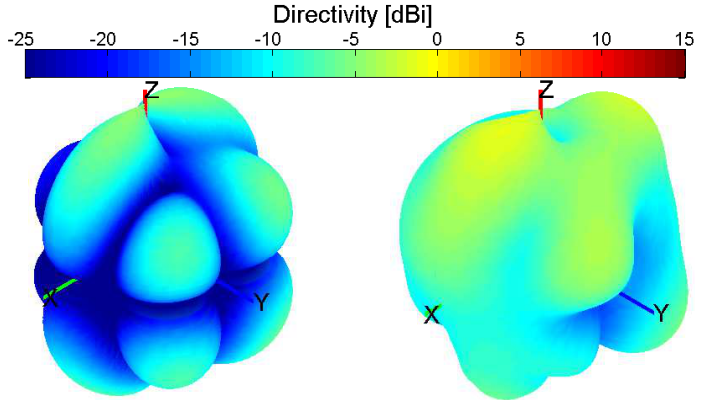

(a)

(b)

Fig. 7. Parasitic array 3D cross-polar directivity radiation pattern. (a) Simulated and (b) measured.

\section{ACKNOWLEDGMENT}

This work was done with the funding of the French National Research Agency as part of the project SOCRATE and the support of the Images et Reseaux cluster of Brittany region, France.

\section{REFERENCES}

[1] I. Uzkov, "An Approach to the Problem of Optimum Directive Antennae Design", Comptes rendues (Doklady) de l'académie des sciences de l'URSS, Vol. 53, no. 1, 1946.

[2] E. N. Gilbert, and S. P. Morgan, "Optimum Design of Directive Antenna Arrays Subject to Random Variations", Bell System Technical Journal, Vol. 34, pp. 637-663, May 1955.

[3] E. E. Altshuler, T. H. O'Donnell, A.D. Yaghjian, and S. R. Best, "A Monopole Superdirective Array", IEEE Transactions on Antennas and Propagation, Vol. 53, no. 8, pp. 2653-2661, August 2005.

[4] T. H. O’Donnell, and A. D. Yaghjian, "Electrically Small Superdirective Arrays Using Parasitic Elements", IEEE Antennas and Propagation Society International Symposium 2006, pp. 3111,3114, 9-14 July 2006.

[5] M. Pigeon, A. Sharaiha, and S. Collardey, "Miniature and Superdirective Two Elements Endfire Antenna Array", 8th European Conference on Antennas and Propagation (EuCAP 2014), 6-11 April 2014.

[6] A. Haskou, A. Sharaiha, and S. Collardey, "Integrating Superdirective Electrically Small Antenna Arrays in PCBs", IEEE Antennas and Wireless Propagation Letters, doi: 10.1109/LAWP.2015.2425913.

[7] A. Clemente, M. Pigeon, L. Rudant, and C. Delaveaud, "Design of a Super Directive Four-Element Compact Antenna Array Using Spherical Wave Expansion, IEEE Transactions on Antennas and Propagation, Vol. 63, no. 11, pp. 4715-4722, November 2015.

[8] N. Yaru, "A Note on Super-Gain Antenna Arrays, in Proceedings of the IRE, Vol. 39, no. 9, pp. 1081-1085, September 1951.

[9] A. Haskou, A. Sharaiha, and S. Collardey, "Design of Small Parasitic Loaded Superdirective End-Fire Antenna Arrays", IEEE Transactions on Antennas and Propagation, Vol. 63, no. 12, pp. 5456-5464, December 2015.

[10] ANSYS HFSS, Pittsburg, PA 15219, USA.

[11] R. F. Harrington, "On the Gain and Beamwidth of Directional Antennas", IRE Transactions on Antennas and Propagation, pp. 219-225, July 1958.

[12] G. Le Fur, C. Lemoine, P. Besnier, A. Sharaiha, "Performances of UWB Wheeler Cap and Reverberation Chamber to Carry Out Efficiency Measurements of Narrowband Antennas", IEEE Antennas and Wireless Propagation Letters, Vol. 8, pp. 332,335, 2009.

[13] [Online]. Available: http://avalanwireless.com/marketing_resources/ product_briefs/AW11-900.pdf 